\title{
HUBUNGAN LAMA MENDERITA DENGAN KEJADIAN NEUROPATI DIABETIKUM PADA PASIEN DIABETES MELITUS
}

\section{THE RELATIONSHIP OF LONG SUFFERING WITH THE EVENT OF DIABETIC NEUROPATY IN DIABETES MELLITUS PATIENTS}

\author{
Maria Karolina Selano ${ }^{凶}$ \\ Sekolah Tinggi IImu Kesehatan Elisabeth Semarang, Jln. Kawi No. 11, Semarang. Indonesia \\ Correspondence Email: mariaselano100284@gmail.com
}

\begin{abstract}
ABSTRAK
Organisasi Internasional Diabetes Federation (IDF) memperkirakan terdapat 463 juta orang pada usia 20-79 tahun di dunia menderita diabetes mellitus (DM) tahun 2019 atau setara dengan angka 9,3\% dari total penduduk pada usia yang sama. Berdasarkan jenis kelamin, IDF memperkirakan prevalensi DM tahun 2019 yaitu 9\% pada perempuan dan 9,65\% pada lakilaki. Prevalensi diabetes meningkat seiring penambahan umur menjadi 19,9\% atau 111,2 juta orang (umur 65-79 tahun). Angka diprediksi meningkat hingga 578 juta di tahun 2030 dan 700 juta di tahun 2045. Pusat Data dan Informasi PERSI (Perhimpunan Rumah Sakit Indonesia), prevalensi penderita DM dengan komplikasi neuropati sebesar lebih dari 50\%. Tujuan untuk mengetahui hubungan lama menderita dengan kejadian neuropati diabetikum pada pasien diabetes melitus Metode secara deskriptif analitik dengan pendekatan cross sectional dan tehnik pengambilan sampel menggunakan purposive sampling sejumlah 84 responden/ pasien diabetes melitus tipe 1 dan tipe 2. Instrumen menggunakan kuesioner dan monofilament test dan data dianalisa dengan uji statistik chi-square. Hasil didapatkan 71 responden (84,5\%) yang lama menderita DM $<5$ tahun, 46 responden $(54,8 \%)$ mengalami neuropati diabetikum dan nilai Asymp Sig 0,942 (P-value = 0,005 ). Karena nilai $0,942>0,005$, maka disimpulkan tidak ada hubungan yang signifikan antara lama menderita dengan kejadian neuropati diabetikum.
\end{abstract}

Kata kunci $\quad$ : diabetes melitus; lama menderita; neuropati diabetikum

\begin{abstract}
The International Diabetes Federation (IDF) estimates that there are 463 million people aged 20-79 years in the world suffering from diabetes mellitus (DM) in 2019, equivalent to 9.3\% of the total population at the same age. Based on gender, IDF estimates that the prevalence of DM in 2019 is $9 \%$ in women and 9.65\% in men. The prevalence of diabetes increases with increasing age to $19.9 \%$ or 111.2 million people (aged 65-79 years). The figure is predicted to increase to 578 million in 2030 and 700 million in 2045. According to the PERSI Data and Information Center (Indonesian Hospital Association), the prevalence of DM sufferers with neuropathic complications is more than $50 \%$. The purpose of this study was to determine the relationship between length of stay and the incidence of diabetic neuropathy in patients with diabetes mellitus. Descriptive analytical method with a cross sectional approach and sampling technique used purposive sampling with a total of 84 respondents/patients with type 1 and type 2 diabetes mellitus. The instrument used a questionnaire and monofilament test and data. analyzed by chi-square statistical test. The results showed that 71 respondents (84.5\%) had long suffered from DM < 5 years, 46 respondents (54.8\%) had diabetic neuropathy and the Asymp Sig value was $0.942(P$-value $=0.005)$. Because the value is $0.942>0.005$, it is concluded that there is no significant relationship between the length of suffering and the incidence of diabetic neuropathy.
\end{abstract}

Keywords: diabetes mellitus; long suffering; diabetic neuropathy

Jurnal SMART Keperawatan is licensed under a Creative Commons Attribution-ShareAlike 4.0 International License 


\section{PENDAHULUAN}

Organisasi Internasional Diabetes Federation (IDF) memproyeksikan jumlah penderita diabetes pada penduduk umur 20-79 tahun pada beberapa negara di dunia yang telah mengidentifikasi 10 negara dengan jumlah penderita tertinggi. China, India dan Amerika serikat menempati urutan tiga teratas dengan jumlah penderita 116,4 juta, 77 juta, dan 31 juta. Indonesia berada di peringkat ke-7 di antara 10 negara dengan jumlah penderita terbanyak, yaitu sebesar 10,7 juta. Indonesia menjadi satu-satunya negara di Asia tenggara pada daftar tersebut, sehingga dapat diperkirakan besarnya kontribusi Indonesia terhadap prevalensi kasus diabetes di Asia tenggara. (Pangribowo S, 2020)

Menurut Permana (2009) penyakit diabetes melitus merupakan penyakit kronis yang akan diderita oleh penderita diabetes seumur hidup dan memiliki progresivitas yang akan terus berjalan sehingga lama - kelamaan akan menimbulkan komplikasi. Lamanya menderita diabetes melitus berhubungan dengan komplikasi diabetes melitus yang dialami oleh pasien. Komplikasi menyebabkan efikasi diri pasien rendah dan mengacu pada penurunan kualitas hidup (Husein, et all.,2010).

Kontrol diabetes melitus yang buruk dapat mengakibatkan hiperglikemia dalam jangka panjang, yang menjadi pemicu beberapa komplikasi yang serius baik makrovaskular maupun mikrovaskular seperti penyakit jantung, penyakit vaskuler perifer, gagal ginjal, kerusakan saraf dan kebutaan. Banyaknya komplikasi yang mengiringi penyakit diabetes melitus telah memberikan kontribusi terjadinya perubahan fisik, psikologis maupun social (Anani et al., 2012).

Neuropati diabetik merupakan salah satu komplikasi yang banyak terjadi pada penderita diabetes melitus tipe 2. Neuropati diabetik merupakan kerusakan saraf yang bersifat fokal atau difus akibat keadaan kadar gula darah yang sangat berlebihan. Komplikasi neuropati diabetic yang dialami penderita diabetes melitus mencapai $50 \%$ dan dapat mempengaruhi fungsi berjalan (Kuate-Tegueu et al.,2015)
Walaupun Diabetes Melitus merupakan penyakit kronik yang tidak dapat menyebabkan kematian secara langsung, tetapi dapat berakibat fatal bila pengelolaannya tidak tepat. Pengelolaan Diabetes Melitus memerlukan penanganan secara multidisiplin yang mencakup terapi non obat dan terapi obat. Penyakit diabetes melitus memerlukan perawatan medis dan penyuluhan untuk self management yang berkesinambungan untuk mencegah komplikasi akut maupun kronis (Utomo, Julianti, \& Pramono, 2011). Manajemen perawatan diri merupakan modal perawatan yang paling tepat untuk seseorang yang menderita penyakit kronik seperti diabetes melitus. Perawatan diri pada pasien DM terfokus pada empat aspek yaitu memonitoring kadar glukosa, variasi nutrisi yang dikonsumsi setiap hari, pengaturan insulin serta latihan fisik secara regular.

Penyakit diabetes melitus merupakan penyakit kronis yang akan diderita oleh penderita diabetes melitus seumur hidup dan memiliki progresivitas yang akan terus berjalan sehingga lama - kelamaan akan menimbulkan komplikasi. Lama seseorang yang menderita diabetes mellitus tergantung pada bagaimana seseorang tersebut dapat mengotrol kadar gula darahnya karena penyakit diabetes mellitus tidak dapat disembuhkan namun, hanya dapat dikendalikan dengan melakukan perawatan seumur hidup (Permana, 2009).

Jumlah penderita Diabetes Melitus (DM) di Kota Semarang sampai dengan bulan Oktober Tahun 2019 mencapai 9 ribu orang, jumlah ini mengalami kenaikan sebesar $10-20$ $\%$. Data dari Puskesmas Srondol dan Puskesmas kagok untuk rata - rata jumlah pasien diabetes yang berkunjung untuk melakukan pemeriksaan dan mengambil obat setiap bulan di Puskesmas adalah sekitar 100 pasien diabetes melitus. Penelitian ini bertujuan untuk mengetahui hubungan lama menderita dengan kejadian neuropati diabetikum pada pasien diabetes melitus.

\section{METODE}

Desain dalam penelitian ini adalah Deskriptif analitik untuk mengetahui hubungan 
antara variabel independent (lama menderita) dan variabel dependent (kejadian neuropati diabetikum). Penelitian ini menggunakan pendekatan Cross Sectional Study.

Populasi adalah seluruh pasien diabetes melitus yang ada di Puskesmas Srondol dan di Puskesmas Kagok Semarang. Sampel berjumlah 84 responden dengan teknik pengambilan sampel menggunakan purposive sampling sesuai dengan kriteria inklusi dan eksklusi. Kriteria inklusi adalah pasien diabetes melitus tipe 1 dan 2 serta bersedia menjadi responden. Sedangkan kriteria eksklusi adalah pasien DM yang mengalami intoleransi aktifitas, pasien DM dengan ulkus diabetikum pada ekstermitas bawah dan pasien diabetes melitus dengan fraktur pada ekstermitas bawah.

Penelitian ini dilakukan di Puskesmas Kota Semarang yaitu Puskemas Srondol dan Puskesmas Kagok semarang pada 10 Juli -09 Agustus 2020. Teknik pengumpulan data menggunakan kuesioer lama menderita diabetes melitus sedangkan untuk mengetahui kejadian neuropati diabetikum dilakukan test sensitivitas kaki (monofilament test). Analisa data dalam penelitian ini dilakukan dengan uji Chi Square.

Penelitian ini telah lulus uji etik di Komisi Etik Fakultas Kedokteran Universitas Diponegoro Semarang dengan nomor etik 104/EC/KEPK/FK-UNDIP/VI/2020. Prinsip dalam etika penelitian ini, yaitu inform consent (lembar persetujuan), anonymity (tanpa nama), confidentiality (kerahasiaan).

\section{HASIL}

Tabel 1 menunjukan data karakteristik usia, jenis kelamin, tingkat pendidikan, lama menderita DM dan kejadian neuropati diabetikum yaitu jumlah responden terbanyak pada usia lansia akhir sebanyak 40 responden $(47,6 \%)$, tingkat pendidikan terbanyak adalah SMA dengan jumlah 37 responden $(44,0 \%)$. Jenis kelamin terbanyak adalah perempuan 59 responden $(70,2 \%)$. Lama menderita $\mathrm{DM}<5$ tahun sebanyak 71 responden (84,5\%), lama menderita DM $\geq 5$ tahun sebanyak 13 responden (15,5\%). Sedangkan untuk kejadian neuropati diabetikum didapatkan hasil sebanyak 46 responden $(54,8 \%)$ menderita neuropati sedangkan 38 responden $(45,2 \%)$ tidak menderita neuropati diabetikum.

Tabel 1. Karakteristik Responden $(n=84)$

\begin{tabular}{lcc}
\hline \multicolumn{1}{c}{ Variabel } & Frekuensi & Prosentase \\
\hline Usia & & \\
a. Lansia awal & 22 & 26,2 \\
b. Lansia akhir & 40 & 47,6 \\
c. Manula & 22 & 26,2 \\
\hline $\begin{array}{l}\text { Pendidikan } \\
\text { a. SD }\end{array}$ & 24 & 28,6 \\
b. SMP & 9 & 10,7 \\
c. SMA & 37 & 44,0 \\
d. Perguruan Tinggi & 14 & 16,7 \\
\hline Jenis Kelamin & & \\
a. Laki-laki & 25 & 29,8 \\
b. Perempuan & 59 & 70,2 \\
\hline Kejadian Neuropati & & \\
Diabetikum & & \\
a. Neuropati & 46 & 54,8 \\
b. Tidak Neuropati & 38 & 45,2 \\
\hline Lama Menderita DM & & \\
$\quad$ a. <5 tahun & 71 & 84,5 \\
$\quad$ b. $\geq 5$ tahun & 13 & 15,5 \\
\hline
\end{tabular}

Berdasarkan tabel 2, diketahui dari 71 responden yang lama menderita $\mathrm{DM}<5$ tahun, terdapat 39 orang (54,9\%) yang mengalami kejadian neuropati diabetikum, sementara dari 13 yang lama menderita $\mathrm{DM} \geq 5$ tahun terdapat 6 orang yang tidak mengalami neuropati diabetikum. Melalui uji statistik dengan continuity correction, didapatkan nilai $\mathrm{p}$-value $=$ 0,942 . Berarti $p$-value $>0,05$ sehingga hipotesa null $(\mathrm{Ho})$ diterima yang menunjukkan bahwa tidak ada hubungan lama menderita dengan kejadian neuropati diabetikum di Puskesmas Srondol dan Puskesmas Kagok Semarang.

Tabel 2. Hubungan Lama menderita DM dengan Kejadian Neuropatik Diabetikum

\begin{tabular}{|c|c|c|c|c|c|c|}
\hline \multirow{3}{*}{$\begin{array}{l}\text { Lama } \\
\text { Menderita } \\
\text { DM }\end{array}$} & \multicolumn{4}{|c|}{ Kejadian Neuropati Diabetikum } & \multirow{3}{*}{ Total } & \multirow{3}{*}{$\begin{array}{c}P \\
\text { value }\end{array}$} \\
\hline & \multicolumn{2}{|c|}{ Neuropati } & \multicolumn{2}{|c|}{ Tidak Neuropati } & & \\
\hline & $f$ & $\%$ & $f$ & $\%$ & & \\
\hline$<5$ Tahun & 39 & 54,9 & 32 & 45,1 & 71 & 12 \\
\hline$\geq 5$ Tahun & 7 & 18,5 & 6 & 81,5 & 13 & 0,942 \\
\hline Total & 46 & 54,8 & 38 & 45,2 & 84 & \\
\hline
\end{tabular}




\section{PEMBAHASAN}

\section{Karakteristik Pasien Diabetes Melitus}

Karakteristik data berdasarkan jenis kelamin didapatkan sebanyak 59 orang $(70,2 \%)$ responden berjenis kelamin perempuan. Menurut Damayanti (2010) perempuan memiliki faktor resiko yang menyebabkan terjadinya diabetes melitus. Faktor resiko tersebut yaitu peningkatan BMI (Body Mass Index), Sindroma siklus bulanan (premenstrual syndrome), dan kehamilan. Perempuan secara fisik memiliki peluang peningkatan BMI (Body Mass Index) yang lebih besar.

Lama menderita diabetes melitus responden di Puskesmas Srondol dan Puskesmas Kagok Semarang, hasil yang diperoleh dari 84 responden yang lama menderita diabetes selama kurang dari 5 tahun berjumlah 71 responden (84,5\%). Lama seorang yang menderita diabetes mellitus disebabkan oleh penyakit diabetes melitus merupakan penyakit yang kronik dengan masa sembuhnya yang lama.

Penyakit diabetes melitus merupakan penyakit kronis yang akan diderita oleh penderita diabetes melitus seumur hidup dan memiliki progresivitas yang akan terus berjalan sehingga lama - kelamaan akan menimbulkan komplikasi. Lama seseorang yang menderita diabetes mellitus tergantung pada bagaimana seseorang tersebut dapat mengotrol kadar gula darahnya karena penyakit diabetes mellitus tidak dapat disembuhkan namun, hanya dapat di kendalikan dengan melakukan perawatan seumur hidup (Permana, 2009)

\section{Kejadian Neuropati Diabetikum}

Frekuensi tertinggi dari kejadian neuropati diabetikum adalah yang mengalami neuropati diabetikum yaitu sebanyak 46 orang (54,8\%). Neuropati diabetik termasuk kelompok gangguan saraf yang disebabkan oleh DM. Pasien DM dari waktu ke waktu dapat berkembang menjadi kerusakan saraf di seluruh tubuh. Beberapa pasien dengan kerusakan saraf tidak memiliki gejala dan mungkin beberapa lainnya mengalami gejala seperti nyeri dan hilangnya rasa pada ekstermitas. Sekitar 60\% sampai 70\% pasien dengan DM dapat mengalami neuropati (Department of health and human services. 2009).

Neuropati berkembang akibat akumulasi produk glukosa yang menghasilkan peningkatan aktivasi enzim aldose reduktase dan sorbitol dehidrogenase. Hal ini menyebabkan konversi glukosa menjadi sorbitol dan fruktosa. Selain itu terjadi peningkatan vasokonstriktor yang berakibat pada iskemia sel saraf. Perkembangan ulkus diabetik pada pasien diabetes melitus didahului oleh riwayat trauma. Neuropati menyebabkan hilangnya sensasi pada kaki yang mengakibatkan trauma yang tidak dapat dirasakan terutama pada daerah yang mendapatkan tekanan berulang. Hal ini mengakibatkan banyak luka trauma yang tidak disadari oleh pasien dan semakin memperburuk perkembangan ulserasi (Clayton W, 2009).

Hasil penelitian Wahyuni (2015) menyatakan pelaksanaan senam kaki diabetik dapat meningkatkan $\mathrm{ABI}$ (Ankle Brachial Index) pada pasien DM tipe 2, sehingga meningkatkan perfusi ke perifer serta pencegahan komplikasi pada pasien diabetes khususnya pada daerah kaki. Penelitian lain yang dilakukan oleh Chaidir (2017) menyatakan terdapat hubungan antara self care dengan kualitas hidup pasien diabetes melitus di wilayah kerja Puskesas Tigo Baleh yang berbanding lurus dan memiliki tingkat korelasi yang sedang.

\section{Hubungan lama menderita dengan} kejadian neuropati diabetikum

Hiperglikemia yang terjadi dari waktu ke waktu dapat menyebabkan kerusakan berbagai sistem tubuh terutama syaraf dan pembuluh darah. Beberapa konsekuensi dari diabetes yang sering terjadi adalah meningkatnya resiko penyakit jantung dan stroke, Neuropati (kerusakan syaraf) di kaki yang meningkatkan kejadian ulkus kaki, infeksi dan bahkan keharusan untuk amputasi kaki. Retinopati diabetikum yang merupakan salah satu penyebab utama kebutaan, terjadi akibat kerusakan pembuluh 
darah kecil di retina, diabetes merupakan salah satu penyebab utama gagal ginjal, risiko kematian penderita diabetes secara umum adalah dua kali lipat dibandingkan bukan penderita diabetes (Pusdatin, 2014).

Hasil uji statistik dengan Continuity Correction, didapatkan bahwa nilai $\mathrm{p}$-value $=$ 0,942 . Berarti $p$-value $>0,05$ sehingga hipotesa null (Ho) diterima yang menunjukkan bahwa tidak ada hubungan antara lama menderita dengan kejadian neuropati diabetikum. Neuropati diabetikum dipengaruhi oleh beberapa mekanisme yang berkontribusi dalam perkembangan kerusakan saraf.

Perubahan metabolik vaskuler pada pasien DM menjadi penyebab kerusakan saraf seperti yang terjadi pada komplikasi mikrovaskuler lainnya yaitu retinopati dan nepropati diabetic (Glow \& Moore, 2014). Oleh karena itu, perkembangan neuropati perifer ini dipengaruhi oleh kontrol glukosa darah pasien DM. Semakin buruk control glukosa pasien DM, semakin besar risiko untuk mengalami neuropati berat. Kontrol glukosa darah pasien digambarkan dengan kadar HbA1C.

Kadar HbA1C dapat memberikan gambaran control gula darah penderita DM dalam rentang waktu $1-3$ bulan (Amran \& Rahman, 2018). Kontrol gula darah yang buruk dapat menyebabkan kondisi hiperglikemia kronik. Hiperglikemia kronik berkontribusi secara signifikan terhadap kerusakan akson yang menjadi dasar berkembangnya neuropati perifer pada pasien DM (Qureshi et al, 2017).

Penelitian oleh Hwang, Pyun dan Kwon (2016), rata - rata kadar HbA1C meningkat pada pasien DM dengan neuropati berat. Faktor lain yang mempengaruhi derajat keparahan neuropati perifer adalah usia, Body Mass Index (BMI) dan durasi menderita DM (Amour et al, 2019). Hal ini sejalan dengan penelitian yang dilakukan oleh Popescu et al (2016) yang menyatakan bahwa usia merupakan faktor independen terhadap derajat keparahan neuropati perifer pada pasien DM.
Faktor lain yang berhubungan dengan derajat keparahan neuropati perifer pada penderita DM adalah kadar lipid darah. Berdasarkan penelitian Irawan, Wuysang dan Goysal (2019), terdapat hubungan bermakna antara kadar lipid dan derajat keparahan neuropati $(p<0,05)$, terutama pada pasien dengan kadar $\mathrm{HbA} 1 \mathrm{C}<7 \%$. Tingginya kadar lipid dapat menginduksi stress oksidatif pada neuron sensorik, sehingga berperan signifikan terhadap progresifitas neuropati perifer.

\section{KESIMPULAN}

Hasil dari penelitian tentang hubungan lama menderita dengan kejadian neuropati diabetikum ini menunjukan bahwa tidak ada hubungan yang signifikan. Hal ini disebabkan karena faktor yang mempengaruhi derajat keparahan dari neuropati perifer pada pasien DM itu bukan hanya pada lama menderita tetapi usia, durasi menderita DM, HBA1C, kadar lipid dan lain sebagainya.

\section{REFERENSI}

Anani, S., Udiyono, A., Ginanjar, P., Fkm Undip, A., \& Bagian Epidemiologi dan, D. (2012). Hubungan Antara Perilaku Pengendalian Diabetes dan Kadar Glukosa Darah Pasien Rawat Jalan Diabetes Melitus (Studi Kasus di RSUD Arjawinangun Kabupaten Cirebon) (Vol. 1). Retrieved from http://ejournals1.undip.ac.id/index.php/jkm

Amour, A. A., Chamba, N., Kayandabila, J., Lyaruu, I. A., Marieke, D., Shao, E. R., \& Howlett, W. (2019). Prevalence, patterns, and factors associated with peripheral neuropathies among diabetic patients at tertiary hospital in the kilimanjaro region: descriptive cross-sectional study from northeastern tanzania. International journal of endocrinology, 2019, 5404781.

Clayton W, Tom A.E, A review of the pathophysiology, classification, and treatment of foot ulcers in diabetic patient. Clinical Diabetes 2009:27:2.

Chaidir, R., Wahyuni, A. S., \& Furkhani, D. W. (2017) Hubungan Self Care Dengan Kualitas Hidup Pasien Diabetes Melitus. Jurnal Endurance. https://doi.org/10.22216/jen.v2i2.1357

Department of health and human services. (2009). Diabetic neuropathies: the nerve damage of diabetes. USA: NIH Publication, 2009. 
Glow, D., \& Moore, P. (2014). Assessing diabetic peripheral neurophaty in primary care. BPJ Issue, 61, 37-47.

Diperoleh tanggal 20 Februari 2020 dari https://bpac.org.nz.

Hussein, R. N.,Khther, S.A., - Hadithi, T.S. (2010). Impact of diabetes on physical and psychological aspects of quality of life of diabetic in Erbil city Iraq. Duhok Med J.4 (2), 45 - 59, http://www.uod.ac/articles files/no 6.9.pdf.

Hwang, J. W., Pyun, S. B., \& Kwon, H. K. (2016). Relationship of vascular factors on electrophysiologic severity of diabetic neuropathy. Annals of rehabilitation medicine, 40(1), 56-65.

Irawan, D., Wuysang, A. D., \& Goysal, Y. (2019). Hubungan kadar lipid darah dengan derajat keparahan neuropati diabetik perifer di rumah sakit wahidin sudirohusodo. Neurona, 37(1), 3741.

Kuate-Tegueu, C., Temfack, E., Ngankou, S., Doumbe, J., Dijentcheu, V. P., \& Kengne, A. P. (2015). Prevalence and determinants of diabetic polyneuropathy in a sub-Saharan African referral hospital. Journal of the Neurological Science, 355(1), 108-112. https://doi.org/10.1016/j.jns.2015.05.035
Pangribowo S. Infodatin -2020-Diabetes-Melitus.Pdf. Jakarta Selatan: Pusat Data Dan Informasi Kementrian Kesehatan Ri; 2020.

Popescu, S., Timar, B., Baderca, F., Simu, M.,Diaconu, L., Velea, I., \& Timar, R. (2016). Age as an independent factor for the development of neuropathy in diabetic patients. Clinical interventions in aging, 11, 313-318.

Pusat Data dan Informasi Kementrian Kesehatan RI. (2014). Infodatin. http://www.depkes.go.id/resources/download/pusd atin/infodatin/infodatin-diabetes.pdf

Qureshi, M.S., Iqbal, M., Zahoor, S. et al. Ambulatory screening of diabetic neuropathy and predictors of its severity in outpatient settings. J Endocrinol Invest 40, 425-430 (2017).

Utomo, A. Y. S., Julianti, H. P., \& Pramono, D. (2011). Hubungan Antara 4 Pilar Pengelolaan Diabetes Melitus Dengan Keberhasilan Pengelolaan Diabetes Melitus Tipe 2. Retrieved from http://eprints.undip.ac.id/32797/

Wahyuni (2015). Senam Kaki Diabetik Efektif MEningkatkan Ankle Brachial Index Pasien Diabetes Melitus Tipe 2. Jurnal Ipteks Terapan. Volume 9 Nomor 2. 